\title{
Language Attitude towards Using Code-Switching as a Medium of Instruction in the Case of Wollo University Kombolcha Institute of Technology, Ethiopia
}

\author{
Mulu Wondimu \\ Department of English Language and Literature, Wollo University, Dessie, Ethiopia \\ P.O box 1145, Dessie, Ethiopia
}

\begin{abstract}
This paper attempts to highlight both the instructors' and students' attitudes towards code switching. It was undertaken in a Governmental University in Ethiopia which prescribes English as the medium of instruction for all courses taught. Descriptive survey design was used in a mixed approach of data analysis. 88 instructors and 320 students were taken as a source of data. Self completed questionnaires and interview as tools of data collection were used. The paper, thus, raises some legitimate concerns of the conflict between the instructors and students attitude and the country policy which certainly has some implications on restrictive use of the medium of instruction in higher education institution. The finding in this study revealed that instructors and students attitude were positive regarding code-switching thus it needs a serious attention from each concerned bodies in the educational hierarchy of Ethiopia to keep balance between the policy and the practitioners attitude
\end{abstract}

Keywords: Kombolcha Institution of Technology, Language Attitudes, Code-Switching

DOI: $10.7176 / \mathrm{RHSS} / 9-21-04$

Publication date: November $30^{\text {th }} 2019$

\section{Introduction}

Background of the Study

As per the literature code switching may be understood as an attempt to recognize the potency of mother tongues as languages of instruction. It also defined as "the use of more than one language in the course of a single communicative episode" Jacobson (1990). Many studies have been done on code-switching of which some argue that it must be encouraged while others feel that it must be discouraged in the classroom with mentioning the significant role English language has worldwide. For instance, scholars like Ellis (1984), Wong-Fillmore (1985), Chaudron (1988), Lightbown (2001), (cited in Liu, 2010) have negative attitude for using code-switching in the classrooms and advocate that any subject instructors' should create a pure linguistics environment of the medium of instruction in the classrooms. They believed that any instructors can help students practice the English language, other than in English-as-a-subject classrooms, in many opportunities. McKenzie and Robert (2010) put it; "Every teacher is an English teacher." Arifffin and Susanti (2011) also emphasis that language skills should be taught by subject area instructors; not left exclusively for the English teacher.

Milroy and Muysken (1995) further explains that academic language skills and competences in different non-linguistic subjects should systematically be developed in close connection with the content, which requires language awareness, language education attitude, and language skills on the part of each subject teacher. Amin (2009) contends that although language specialists play a key role in L2-medium schools, language-sensitive developments in schools are largely unsuccessful if left only to language instructors. More specifically, as students have little opportunity for exposure to the English language outside the classroom in many of the world nation and instructors are normally the only expert users of the English language either way teaching it as a subject or using it as medium of instruction, instructors, therefore, should maximize the use English in their classroom. Ihemere (2006) extends this idea saying that instructors should provide their students with a rich environment by using the English language not only for academic content instruction but also for disciplinary and managerial matters as well. Driven by the same impetus Mahathir (2003) suggested that the motivation behind the move towards using an English language in teaching is first and foremost to improve the local students' English language competence is an asset in seeking employment in the globalised economic world. In addition, the vast amount of information is currently available in English. Thus, it is hoped that the availability of English and more exposure to the language in the classroom can contribute to the students' English language competence, which is the key to access information in a variety of fields and also to facilitate the acquisition of knowledge. He also added that, the prestige the language has in serving communities being a language of research and publication and commerce and its utility for access to employments well made it the educational issue of many countries worldwide. Those aforementioned scholars therefore believed that instructors should not switch the English code to either for the reason to compensate the linguistic gap they would have themselves or for the purpose of meeting the demand of their linguistic group.

On the contrary, researchers like Vazquez-Faria (1982), Levine (2003), Chen (2004) (cited in Liu, 2010) 
argue for the positive aspects of code-switching by instructors in the classrooms and claimed that code-switching to L1 by instructors will make understanding easy among the students and learning will be accelerated. Mingfa (2011) also derived the same opinion from his research and suggests for the usage of code-switching technique in the classrooms. Merritt (1992) while investigating code-switching in Kenyan primary classrooms also drew the same results and concluded that "skilful use of code switching can lead to better teacher-student classroom communication boosts the quality of teaching, help students' comprehension, and foster a healthier and friendlier teacher-student relationship, especially for the lower levels.

Attitudinal researches have shown that a monolingual speaker tends to have a more negative view of codeswitching. A study conducted by Margarita (1988) for instance, has shown that Ciudad Juarez residents rated code-switching low in terms of understandability, attractiveness and correctness. Studies conducted on bilingual speakers have also shown similar negative attitude result on code-switching as the response of the subject under Abdullah (2010) study moreover, has shown that continuous use of code-switching brought covert prestige on learners.

\section{Statement of the Problem}

In the curriculum which appeared in 1963/4, complete distinction in the medium of instruction in primary and secondary schools was announced. Then the medium of instruction from the first to sixth grade became Amharic, whereas English was taught as a subject starting from the third grade to sixth grade as a second language and remained as a medium of instruction from grade seven through tertiary education in Ethiopian.

The increasing interest in the current educational policy for improving learners' expertise in English language thought that English has multipurpose roles in Ethiopia. For instance, it is the only language which keeps us in touch with the rest of the world. That is why the document of the Ministry of Education (MoE, 2007) reveals that English is a corner stone in the development of Ethiopia's education for the purpose of research and publication, international communication, international commerce and technology transfer. What is more, it is not only that English has a multipurpose role in Ethiopia but also that the determining factor the language has on university graduate students to be survive later in the competitive world. In addition, in Ethiopia alike to the other world with the exception of few situations in many of the circumstances, an exam either it is written or oral for the purpose of hiring an individual would be prepared via English language. These all situations, therefore, demands the learners a least of language command which serves them to be fittest in the real world.

To this effect, in Ethiopia endeavours have been carried out to boost up the status of English in general and to intensify the English proficiency of instructors and students in particular. That is why it is taught as a subject at all levels being given the highest number of periods, at an average of one period a day, Monday through Friday, while other subjects (Social Studies and Sciences, for example, are comparatively given a maximum of three periods a week) and declared as medium of classroom communication in the secondary and tertiary level.

However, this fact remain true in the educational system of Ethiopia, practitioner instructors and students in secondary and tertiary level switch the code of the instructional language and use their own $\mathrm{L}_{1}$ for the communication they would have in the classroom. The researcher drawn this fact from her informal experiential knowledge she developed as a teacher both in the secondary schools and Universities for several years. In the Ethiopian context, for instance, an investigation which has been elaborating the essence of code, code-switching and other related aspects of code-switching has been carried out by Tamiru and Italo (2014) entitled on "Instructors' Help of Students to Use English in Selected Secondary Schools at Nekemte." And the finding of their research indicated that majority of male and female EFL instructors witnessed, instructors switch the instructional language it is not the reason that they lack linguistic competence and would not want offer language sensitivity in content instruction; rather it may be because they have not been made aware of how to do it. Other research also conducted by Dereje and Abiy (2015), on a topic "Male and Female Secondary School EFL Instructors' Code-Switching to L1 in their Classes: their Attitudes, Reasons and Beliefs about the Functions of Code-Switching." In comparison to Tamiru and Italo (2014), they come up a different view in their research as their finding indicated.

They found that the majority of male and female EFL instructors witnessed, the main factor that influences instructors to use Amharic in their classroom is their low competence in the English language or their inability to fill gaps of their speech in the target language. Though studies have been conducted on the topic under investigation in the current study, each of them paid attention for the existing situation in Secondary and preparatory schools. Code switching in relation to the learning and teaching situation in the universities of Ethiopia in general and science and technology universities in particular has seemed overlooked. That is why; this paper aims to assess instructors' and students' attitude towards the communicative behaviour in Wollo University Kombolcha Institute of Technology, Ethiopia. With this general purpose in mind, the study brought possible answers for the following research questions and objectives. 


\section{Basic Research Questions}

- What is the attitude of lecturers in Wollo University: Kombolcha Institute of Technological Campus towards code-switching of English with their $\mathrm{L}_{1}$ in their interaction in the classroom?

- What is the attitude of students in Wollo University: Kombolcha Institute of Technological Campus towards code-switching of English $\mathrm{L}_{1}$ in their interaction in the classroom?

\section{General objective of the study}

The main objective of this study is to assess the language attitude of both instructors and students in Wollo University: Kombolcha Institution of Technology Campus

\section{Specific objectives of the study}

The specific objectives of the study are:

- To investigate lecturers' attitude towards Code-switching of English with their native languages in the case of Wollo University: Kombolcha Institute of Technological Campus.

- To assess students' attitude towards Code-switching of English with their native languages in the case of Wollo University: Kombolcha Institute of Technological Campus.

\section{Significances of the Study}

The findings brought in this study will create awareness both for instructors and students about their attitude and the concerned bodies as well. Moreover, it will not only create awareness to the university community about the classrooms but also gives an insight to other linguist researchers who are interested in studying further about code switching in the classroom where English is used as medium of instruction.

\section{Methodology of the Study \\ Research Design}

In line with the objective of the study, the type of the research is descriptive study. The researcher selected this research design as it is suitable to describe well the existing situation of code-switching in the selected site later. Moreover, since the research targets to assess attitude, it is found important to use different tools and get hold of reliable and pertinent information from the participants of the study about the attitude of instructors and students on code-switching as a result on the type of information and data analysis the design, therefore, grouped under both qualitative and quantitative or mixed approach.

\section{Population/ subject of the study}

The subjects of this study are both students and instructors in Kombolcha Institute of Technological in 2009 A. C. 7,460 in total number of which 7000 is students and the rest 460 are instructors. As far as the researcher believe that the problem of code-switching is commonly existing in every facet of the teaching and learning in the classroom. However, reason behind taking the aforementioned population under this investigation is, because Kombolcha Institute of Technology is, a place where hard science like engineering, computer science etc were given for students.

\section{Sampling techniques}

The sources of data for this study are different groups of respondents that consist of instructors' and students'. Since taking all of the population in this study makes the job tricky, the researcher therefore decide to select representative sample for the data gather via questionnaire and interview. In order to determine the sample size the researcher use a scientific formula $\mathrm{n}=\left(\mathrm{Za} / 2^{2}\right) \mathrm{P}(1-\mathrm{p}) / \mathrm{w}$ for a population $\geq 10,000$ with considering $\mathrm{P}$ is $50=\mathrm{P}$ (0.05). It is for the reason that, the researcher did not get research previously conducted on this issue to use as a bridge for reference. Using the aforementioned formula the researcher determined 320 for the population of students and 80 for the population of instructors sample size.

\section{Data gathering Instruments}

On the aim of achieving the intended objective three main data gathering tools were utilized. These are: questionnaire and interview.

\section{Questionnaire}

Believing that they had taken training and workshop, and had more awareness about the issue under investigation, the researcher invited professional people for the preparation of the questionnaire. Afterwards, with hocking their experience from the literature the researcher prepare the questionnaire in collaboration with those professionals. The items in the questionnaire were closed-ended which rated strongly agree to strongly 
disagree.

\section{Interview}

The purpose of the interview is mainly to obtain detail information from the instructors about the problem under investigation. The researcher mainly brings into play it as source of wise information on the problem than the self-reported questionnaire. With regards to its development, the researcher prepared semi-structured interview questions based on the review of literature and her/his experience of engagement. 10 instructors were taken for the interview.

\section{Data Gathering Procedure}

Before the onset of data gathering, the researcher had session for discussion with their assistance on how would data be gathered. Hereafter, based on the informed procedure the data collectors in collaboration with the researcher distributed and collected the questioners for all samples in the same period. What is more, in order to reduce the artificiality of the respondents on their response; the researcher conducted the interview in parallel secession of data collection through questionnaire.

\section{Data Analysis Procedure}

This study employs both quantitative and qualitative data analysis too. The quantitative data (i.e. data from questionnaire) and percentage was employed. Data from interview analyzed qualitatively. For the qualitative data analysis, the following processes were employed: first, after the data from the respondents recorded, the researcher first organized the verbal data emerging from interview by theme to make it suitable for ensuring analysis. Second close readings of the raw text so as to manage where the themes and details have to be clearly understood were done. And finally, on the basis of the analysis framework, the data obtain from questionnaire and interview presented by triangulating each other.

\section{Data Interpretation and Discussion}

The work in this chapter is about interpretation and discussion of datum gathered on variables attitude and reasons towards code-switching. Regarding datum in the table below, all the 15 items found in different table are standing for the same purpose. They are designed for gathering data about instructors and students attitude towards code-switching. Though they have the same purpose, they are somehow different in their stands' or intention's. That is why, the researcher listed out items for attitude in three different tables according to their stands' or intention's. Items 1, 2, 3, 4, 5, 7, 9 and 10 for instance, developed for the purpose of collecting data on positive view of using code-switching in the classroom, 6, 8, 11, 12 and 14 on the other hand, are designed to collect data about the negative view towards code-switching. And item number 13 and 15 finally, is about the overall attitudinal reaction towards code-switch use in the classroom. What is more, data from interview was presented by categorized themes under the interview items.

\section{Data from Interview}

As mentioned in methodology part interview was one of the tools via which data was gathered. Prior to holding the interview, the researcher found instructors who were willing to be interviewed with explaining the intention of the research generally but not specifically on point. Having permitted the researcher therefore took each volunteer teacher demographic information. For instance, among all the teachers observed, four were females and the rest six were male. Connecting to their teaching experience five of them belonged to the range of two to five years of experience in teaching. And the only two of them had six and eight years of experience in teaching. The remaining three had one year experience. Above and beyond, except four teachers, the rest had attend and completed their second degree on different field of studies. Following the researcher conducted the interview with 10 instructors.

The interview has been done based up on semi-structured items listed below

1. How do you view? How code-switching makes students understand new concepts easily?

2. What is your opinion on code-switching purpose to creating unforgettable knowledge?

"Because understanding is highly dependent on the knowledge of the language used for communication, to comprehend a concept learners have to have a pre-requite knowledge of the language vocabulary, grammar, syntax etc used for communication." Suggesting their View mentioned above, six of the instructors replied that because our students had have more exposure to their $\mathrm{L}_{1}$ when they attend their education in the elementary, and secondary preparatory level, for us code-switching in the university does not become a constrain for them to understand the concepts which are going to explained through switching the code. They also have similar point of view on the function of CS to create unforgettable knowledge. "Instead of creating enabling environment for using the medium of instruction whereby learners could develop a sense of global citizen in one hand, and gradually resolve the trend they brought from their lower level learning on the other hand; we kept learners in the 
same scenarios they had yesterday in their elementary and secondary preparatory school learning." Forwarding the view aforementioned the other three instructors explained that of course we instructors felt that switching the code helps our students to understand the concept we need to explain to them, our action we believed results a double burden to our students.

First: Learners can't struggle to see their status regarding the medium of instruction. Second: They can't be a productive global citizen. Because whatever knowledge we have it is language which makes us able to bring our knowledge to our service customers and providers either in the written or oral forms. If so, learners with less exposure of the global language like English may not be competent enough to share his/her expertise as efficient as those who have tremendous exposure.

Only one instructor among the ten said that as far as code-switching does not the only contributor factors for learners understand, it may difficult to say certainly that code-switching help my learners to understand the concept I explain through it. To me, it may or may not be.

3. How do you perceive the say "Instructors switching of the medium of instruction by once own $L_{1}$ creates a gap between students to understand concepts similarly."

4. Many linguists said that people in the world were categorized under either bilingual or multilingual. So suppose our context, as far as we are diversify up on culture, linguistic, religion etc elements, the linguistic make up you did have may different from your student linguistic make up. So how do you feel switching the code by once one linguistic make up makes you able to accommodate all students in your classroom teaching?

5. How do you feel the controversy between teaching using code-switching and examining using only the medium of instruction?

Eight of the ten instructors regarding item number 3 and 4 students diversity may not be a problem. It is because, since the nearby time students' university placement has been done by giving special attention to learner's preferred universities and fields hence we have almost homogenous students in university since many students prefer universities which found in their own region due different personal reasons. Whereas, the rest two instructors said that though homogeneity may true for the majority, the fact of acknowledging the minority is the responsibility of the instructors. They said "The say the majority governed the minority may not be functional in the learning-teaching process. Thus instructors should do in an inclusive way via which they can address both the homogeneity and heterogeneity. Unless instructors' striving to address the minority in learningteaching process, holistic change is not yet real"

"Though English language was acknowledged as a medium of instruction starting from grade 7 since 1994 in educational policy of our country, the reality we have in practice did not manifest this." The controversy between teaching through code-switching and using the medium of instructional language exclusively for examination four of the instructors said that it has its own influence on the student's performance. The rest six instructors on the other hand, stated that though exclusive use of the instructional language in examination seems challengeable, no difference in student's performance even their $L_{1}$ was used for the examination purpose. It is because it is not only code-switching which would be contributor for the student's performance in exam. 
Data from Questionnaire

Table 1: Analysis of instructors' and students' attitudinal reaction to wards items of the negative concept relating code-switching use.

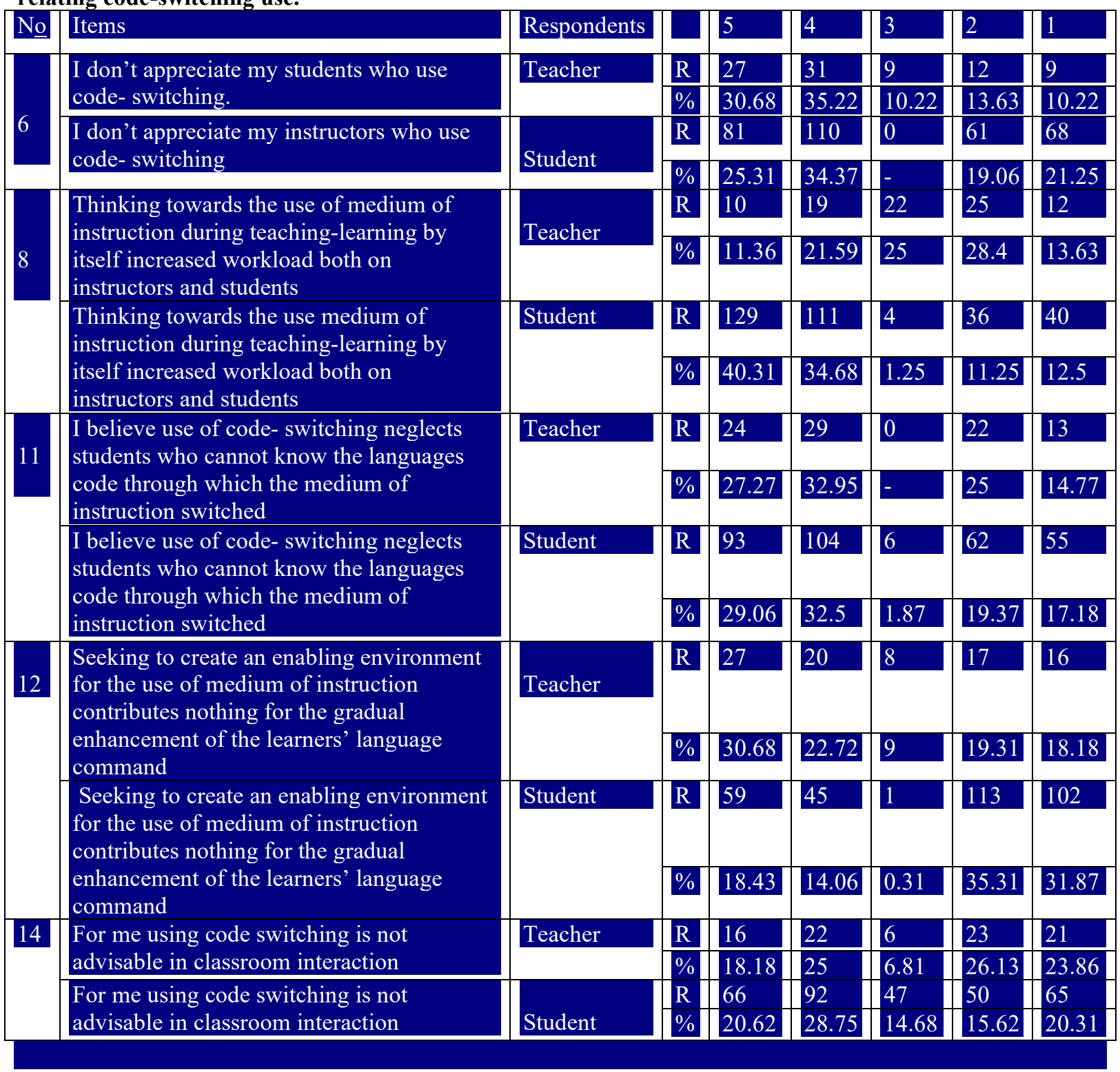

As far as item number $6,8,11,12$, and 14 are negative in their view; the implication of the result from these items was not directly related to the scale. It is to mean, if the response fallen at the positive scale, it is negative for the implication. Conversely, if it is at the negative scale, the implication is positive.

As illustrated in table 1 and in its summary as well, except item numbers 8 and 14 the tendency of the teacher's respondents for items 6,11 and 12 was towards the scale 5 and 4 . To put things in nutshell for item number 8 and 14, $25(28.4 \%)$ and $12(13.63 \%)$ and 23(26.13\%) and 21(23.86\%) of the 88 instructors responded strongly disagree and disagree respectively a sum of (42.03\%) and (49.99\%) as observed in the summary above. For item number 6,11 , and 12 on the other hand, 27(30.68\%) and 31(35.22\%) a total (65.9\%), $24(27.27 \%)$ and $29(32.95 \%)$ a total of $(60.22 \%), 27(30.68 \%)$ and $20(22.72 \%)$ a sum of $(53.4 \%)$ instructors response point out towards the positive scales strongly agree and agree in their respective order. Student respondents whereas provide a deferent answer for the items. Except item number 12, their response was highly attached to strongly agree and agree for item number $6,8,11$, and 14. But for item number 12 their responses pertain to the negative scale strongly disagree and disagree. To illustrate, $81(25.31 \%)$ and $110(34.37 \%)$ a total of $(59.68 \%)$, $129(40.31 \%)$ and $111(34.68 \%)$ a total of $(74.99 \%), 93(29.06 \%)$ and $104(32.5 \%)$ a sum of $(61.56 \%), 66(20.62 \%)$ and $92(28.75 \%)$ a sum of $(49.37 \%)$ student respondents responded strongly agree and agree for item number 6,8 , 11 , and 14 respectively. But for item number 12,113(35.31\%) and 102(31.87\%) a sum of (67.18\%) student respondent responses' inclined to strongly disagree and disagree. What is more, pertaining to the scale undecided, 
except item number 8 to which 22(25\%) instructors' respondents responded undecided, few was in number for the rest items whom responded undecided.

Table2: Analysis instructors' and students' attitudinal reaction to wards items of the positive concept towards code-switching.

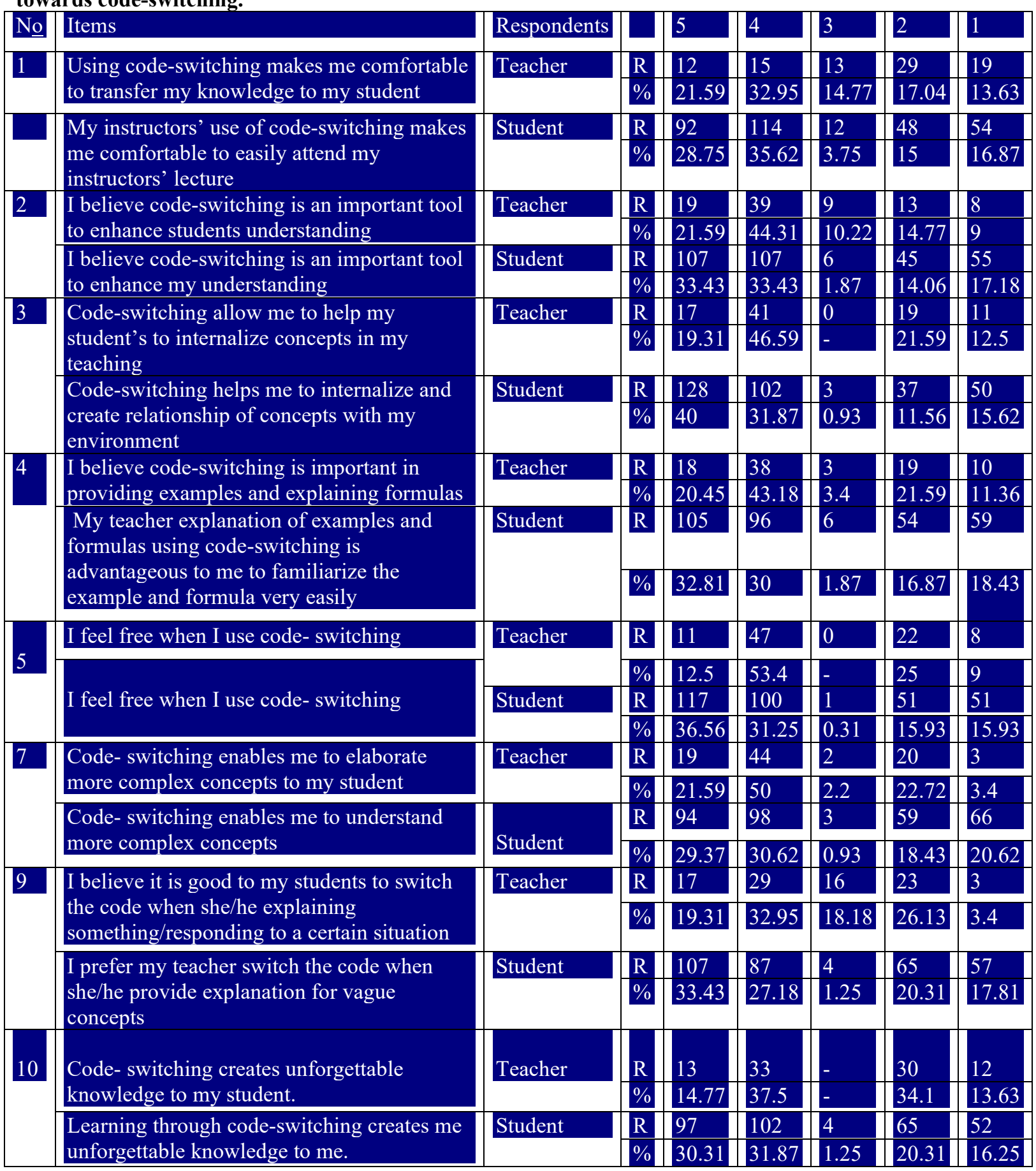

Table 2 displays both instructors and students response regards to the positive view to code-switching in the classroom. Thus, as observed above both in the table and its summary, except question number 1, 29(17.04\%) and $19(13.63 \%)$ a sum of (54.54\%) of teacher respondents react to strongly disagree and disagree, for many of the items instructors response inclined to strongly agree and agree. The responses of students similarly, adheres to the scale strongly agree and agree for all item cases. Though the job seems redundant, it is sound to state here both the instructors and students respondents' number and percent under each items case so as to make the skeleton of interpretation more clear. In contrast to the teacher respondents $92(28.75 \%)$ and $114(35.62 \%)$ a total of $(64.37 \%)$ student respondents agreement laid on strongly agree and agree for item number 1 . Except this difference both the instructors' and students' response for the rest items almost fall into the same categories under strongly agree and agree though there was exist slight difference in their degree of reaction for strongly 
agree and agree and in their sum as well. To simplify it, among the 88 teacher and 320 student respondents $19(21.59 \%)$ and $39(44.31 \%)$ instructors and $107(33.43 \%)$ and $107(33.43 \%)$ students, for item number 2 , $17(19.31 \%)$ and $41(46.59 \%)$ of teacher and $128(40 \%)$ and $102(31.87 \%)$ student for item number $3,18(20.45 \%)$ and $38(43.18 \%)$ teacher and $105(32.81 \%)$ and $96(30 \%)$ students for item number $4,11(12.5 \%)$ and $47(53.4 \%)$ instructors and $117(36.565 \%)$ and $100(31.25 \%)$ students for item number $5,19(21.59 \%)$ and $44(50 \%)$ instructors and $94(29.37 \%)$ and $98(30.62 \%)$ students for item number 7, 17(19.31\%) and 29(32.95\%) instructors and $107(33.43 \%)$ and $87(27.18 \%)$ students for item number $9,13(14.77 \%)$ and $33(37.5 \%)$ instructors and $97(30.31 \%)$ and $102(31.87 \%)$ students for item number 10 responded strongly agree and agree.

Table 3: Analysis of instructors' and students' overall attitudinal reaction towards code-switching

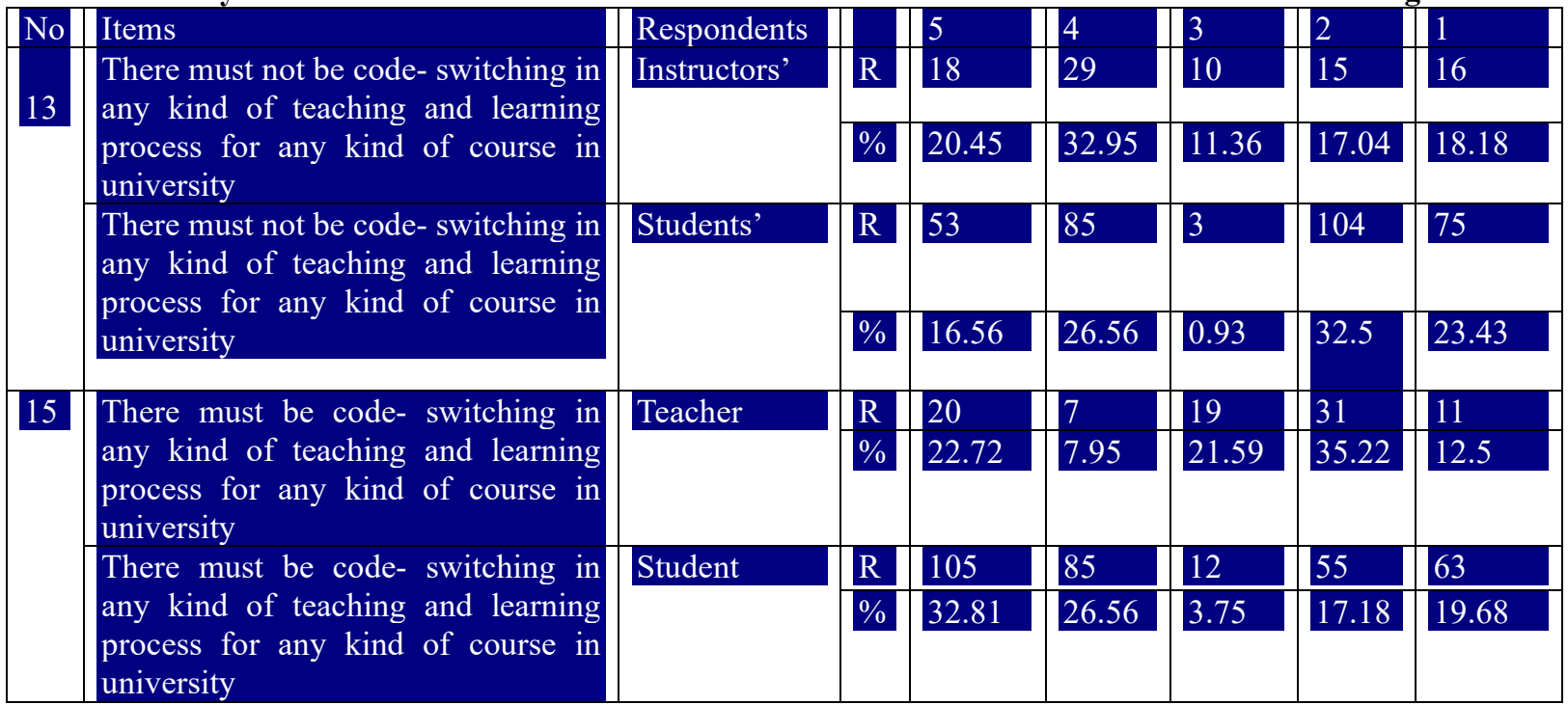

Table 3 illustrate the overall attitudinal reaction of both instructor and student respondents towards codeswitching. As the data in the aforementioned summary indicate, divergence was observed between the instructor's and student's response for items 13 and 15. While their instructor's general attitude frame towards code-switching was negative, the student's responses showed that students have a positive attitude to codeswitching. From the discrepancy it is possible to infer instructors and student's attitude was at two extreme point of the continuum for the use of code-switching in the teaching- learning process. From the data in table 1, 2, and 3 and the interview it is possible to infer

Though the instructor's response for item numbers 13 and 15 in table 3 revealed that instructors wanted to use the medium of instruction in the classroom, conversely, the fact in their responses for items number 2, 3, 4, 5, $7,9,10$, and 12 in table 1 and 2 indicate that the majorities of the instructors have positive attitude towards codeswitching. When viewing code-switching as a common phenomenon in the learning- teaching process in the world, it is interesting to compare the findings of this study to other studies that have been conducted nationally and internationally on the topic. The finding regarding instructors' attitude in this study is similar with Liu (2010) and Moses (2014) findings. Liu (2010) discovered that Chinese University instructors and students attitude towards code-switching taking 60 instructors and 261 students as participants.

His finding revealed that $80 \%$ of the instructors' participants have positive attitude to code-switching. Moses (2014) also conducted a study entitled "The Use of English and Code Switching in the Teaching and Learning of Technology in some Schools in Eastern Cape Province, South Africa." And the finding of his study indicates that $86.1 \%$ of the teacher participants did have positive attitude towards code switching. Students also found in this study with positive attitude towards the code-switching they have with themselves and with their teachers in the classroom. Students' responses for all the items indicate that positive agreement.

This research also brought similar finding with Liu (2010) and Moses (2014) regarding student attitude too. Because the majorities of the instructor respondents disagree with restrictive use of code-switching in the classroom as their responses for items number 13 and 15 indicated. Accordingly, though discrepancy was observed in the instructors' responses for items 1-12 and 13 and 15 findings of this study also concur with Dereje and Abiy (2015) finding. Their finding indicates that the majority of Male and Female EFL instructors claimed $90 \%$ use of the medium of instruction in their teaching in the classroom. In the current study also it possible to deduce from the responses of instructors' for item number 13 and 15, they want to use the medium of instruction. Hence, the possible justification for the positive attitude of the instructor towards code-switching that the researcher anticipates may derive from the trend in which the instructors themselves came through in their learning as student. 


\section{Conclusion}

Assess the language attitude of instructors and students towards code-switching in Wollo University: Kombolcha Institute of Technology Campus was the main purpose of this study the research tried to answers the basic questions what is the attitude of lecturers towards code-switching of English with their $\mathrm{L}_{1}$ in their interaction in the classroom and what is the attitude of students towards code-switching of English with their $\mathrm{L}_{1}$ in their interaction in the classroom?

With all the data gathered through the questionnaire and the interview the majorities of instructors and students in Wollo University kombolcha Institute of Technology found: Have positive attitude towards codeswitching. Instructors and students discrepancy was observed. Students restrictively acknowledge the use of code switching whereas their instructors response shown a tendency to the use of the medium of instruction. So from this it is sound to forward an implication for further study. In this area it may be sound to conduct a study which assesses instructor's reasons and level of use of code-switching in the classroom.

\section{Recommendation}

The findings in this study revealed that both instructors and students have positive attitude towards codeswitching. The researcher, therefore, in line with the findings recommend the following.

- Instructors in the university should make themselves ready to keep a balance between their attitude and the globalized world requirement and prepare their students accordingly of the national and international needs.

- As far as diversity of students concerned, they also expected to keep balance between their students' diversity and their attitude.

- Students themselves should work towards not only for achieving a good result in academic performance but also for meeting the demand of the globalized world later they will expose after their graduation. Finally, serious attention is required from each concerned bodies in the educational hierarchy of Ethiopia to keep balance between the policy and the practitioner attitude.

\section{References}

Abdullah A. A. (2010) .Students' Language Attitude towards Using Code-Switching as a Medium of Instruction in the College of Health Sciences: an exploratory study. Published article on journal of

Amin T. (2009). Language of instruction and science education in the Arab World: Toward a situated research agenda. The world of science education: Arab states. S.B. a. Z. Dagher. Rotterdam. The Netherlands, Sense Publishers.

Arifffi K. \& Susanti M.(2011). Code-Switching and Code-Mixing of English and Bahasa Malaysia in Contentbased Classrooms: Frequency and Attitudes. Linguistics 5,1:220.

Dereje A. and Abiy Y. (2015), Male and Female Secondary School EFL Teachers' CodeSwitching to L1 in their Classes: their Attitudes, Reasons and Beliefs about the Functions of Code-Switching. Published article on journal of Ethiop. J. Educ. \& Sc. Retrieved on Sept 15,2008 from https://www.ajol.info/index.php/ejesc/article/view/136451

Jacobson R. (1990). Code switching as a worldwide phenomenon. New York: Peter Lang

Ihemere K.U. (2006).An Integral approach to the study of language attitudes and change in Nigeria: The Case of Ikwerre of port Harcourt city. 194 - 207. Selected Proceedings of the 36th annual conference on African linguistics.

Liu J. (2010). Teachers code switching to L1 in EFL Classroom: The Open Applied Linguistics Journal,2010,3, 10-23.

Mahadhir M. (2007). Code-switching in the English language classrooms in Kuching secondary schools. Sarawak Museum Journal, Special Issue No. 7 on Social Sciences and Humanities, LXTV(85), 197-219.

Margarita H. (1988). Perceptions of Spanish-English Code-Switching in Juarez, Mexico. Published article on disc@unm.edu. Retrieved on May 2008 from https://digitalrepository.unm.edu/laii_research/14. Download.

McKenzie R. (2010). The Social psychology of English as a global language: Attitudes, awareness and identity in the Japanese context. United Kingdom: Springer.

Merritt M. A. (1992). Socializing Multilingualism: Determinants of Code-Switching in Kenyan Primary Classrooms. Journal of Multilingual and Multicultural Development 13 (1/2), 103- 124.

Milroy L. and Muysken P. (1995). One Speaker, Two Languages: Cross-Disciplinary Perspectives on CodeSwitching. New York: Cambridge University Press.

Mingfa Y. (2011). On Attitudes to Teachers' Code switching in EFL Classes: World Journal of English Language, 2011, Volume 1, No. 1

MoE. (2007). Guidelines for English language enhancement in our schools: A set of practical guidelines to help promote the use of English. Addis Ababa: USAID.

Mosses, M.(2014) The Use of English and Code Switching in the Teaching and Learning of Technology in some 
Schools in Eastern Cape Province, South Africa. Published article on Mediterranean Journal of Social Sciences: Retrieved on April 282007 from citeseerx.ist.psu.edu/viewdoc/download?doi=10.1.1.859.

Tamiru, O. and Italo, B. (2014) Teachers' Help of Students to Use English in Selected Secondary Schools at Nekemte, Ethiopia. Published article on journal of STAR. Retrieved on March 232007 from https://www.ajol.info/index.php/star/article/view/112787 